\title{
Taking the First Step with Systems Theorizing in Information Systems:
}

\section{A response}

\author{
Dionysios S. Demetis ${ }^{\mathrm{a}}$, Allen S. Lee ${ }^{\mathrm{b}}$ \\ ${ }^{a}$ Hull University Business School, Centre for Systems Studies, University of Hull, HU6 7RX, United Kingdom \\ ${ }^{b}$ School of Business, Virginia Commonwealth University, 301 West Main Street, Richmond, VA 23284-4000, \\ United States
}

\begin{abstract}
We address the commentaries of Robey and Mikhaeil, of Mingers, and of Schultze which provided responses to our paper, "Crafting theory to satisfy the requirements of systems science." We find their responses useful for reflecting on the development of the role of systems theorising within information systems research and provide our reaction in order to clarify several fundamental considerations pertaining to 1) our proposed set of requirements for systems theorizing, 2) the need for explicit systems theorizing, 3) the supposed overall neglect of systems science, 4) the communicability of systems theory and the path of grand theories, 5) emergence, the observer, and other considerations, and 6) systems theory from the perspective of sociomateriality.
\end{abstract}

Keywords: systems theory

\section{Introduction}

In our essay (Demetis \& Lee, 2016), we deliberately presented just one possible set of requirements for systems science to satisfy. Our purpose was for the essay to open up a discussion on the role of systems theory in Information Systems (IS) research. Based on three reactions to our essay (Mingers, 2017; Robey \& Mikhaeil, 2016; Schultze, 2017), we are pleased that it has "struck a nerve." This is exactly the sort of response that we feel is needed for the overall field of IS to take systems theory seriously for the first time. And, as in undertaking any journey, it is necessary for the field to begin by taking the first step.

We address the commentary of Robey and Mikhaeil and the commentary of Mingers in the first part of this response, and the commentary of Schultze in the second part. We address the following points: 1) our proposed set of requirements for systems theorizing, 2) the need for explicit systems theorizing, 3) the supposed overall neglect of systems science, 4) the communicability of systems theory and the path of grand theories, 5) emergence, the observer, and other considerations, and 6) systems theory from the perspective of sociomateriality. 


\section{On our proposed set of requirements for systems theorizing}

In our essay (Demetis \& Lee, 2016), we proposed a set of requirements for a systems theory to satisfy. In order to emphasize the context of their development, we would like to highlight the following direct quotations from our essay:

The purpose is not to present all features of systems science... (p.116)

Based on our preceding discussion of some basics of systems science in general and Luhmann's systems theory in particular, we offer the following as a set of requirements for a theory to satisfy in order to be considered a systems theory. Given the extensive diversity of systems approaches, the requirements we offer make up but one possible set, where the set is sufficient to be illustrative of systems theorizing. (p.121)

We emphasize that what we provide in this paper is not a universal set of systems criteria but just one possible set out of many. (p.126)

All three commentaries argue from a standpoint as if we present our six requirements as the only set of requirements for systems theorizing. For instance, Mingers (2017) says, “The first problem is that the field of systems is so broad as to defy any sort of succinct definition or description as this paper attempts" (p.67) and "The second problem is that even this area is dealt with in a rather cursory manner. In terms of any detail, it covers only a single theorist Niklas Luhmann” (p. 67) where Mingers characterizes Luhmann as "rather marginal, highly abstract and complex, and not really a representative of GST” (p. 67), ignores our distinction between GST/LST (and second order cybernetics), and underplays Luhmann's contribution. ${ }^{1}$ Worth noting is that King and Thornhill (2003) offer their own detailed analysis of how Mingers' view on Luhmann is “misleading in certain key aspects... [and] involves a misunderstanding of Luhmann's sociology and a failure to appreciate the overriding objective that Luhmann set himself in his theoretical work” (2003, p. 276)

Minger's “partial history of systems thinking” is useful; yet, the tomes of past work on systems thinking and systems theory that Mingers brings up have largely been collecting dust as far as the information systems discipline is concerned. The mere existence of knowledge (here, knowledge about systems) is no guarantee in itself that the knowledge will be used. Knowledge does not implement itself. Simply pointing to the existence of vast tomes of past, dormant research is a futile effort. How to resurrect them — or rather, in the

\footnotetext{
${ }^{1}$ GST is general systems theory. LST is Luhmannian systems theory.
} 
information systems discipline, to bring them to life in the first place and attempt to implement even a few principles in an application domain is the point that our essay addressed.

Mingers also offers his own set of criteria for what constitutes systems theorizing and we welcome yet additional criteria from other scholars, so as to more fully illustrate the many different facets of systems thinking. This gives us the opportunity to mention (as we do use concepts from GST and LST) that we are not calling for a GST-only application of systems concepts to IS. Our addition of requirements from LST is one way (out of many) for emphasizing some core developments in systems theory. We find Robey and Mikhaeil's perspective on this as particularly fruitful when they mention that "Hopefully, interest in older systems theory, while looking backward, can also serve as a springboard for fresh ideas that engage directly with contemporary technologies and society” (p. 130).

\section{The need for explicit systems theorizing}

Our position, which is that it is necessary to begin a journey by taking the first step, directly contradicts the protestations framed as "déjà vu" by Robey and Mikhaeil and "back to the future” by Mingers, whose phrasings presume that the journey had begun long ago. Instead, the reality is that the field of information systems as a whole has never seriously entertained systems theory in the first place. We have noted a few individual exceptions like Checkland (2000) and Alter (2001), but there has existed no overall body of literature indicating a systems movement in the field of information systems to which they or others have contributed.

An indicative example of how Robey and Mikhaeil perceive the role of systems theory is evident in the following passage (2016, pp. 128-129).

Despite overall neglect of systems science, GST [General Systems Theory] concepts crept into organization studies and IS and remain there. For examples, theoretical approaches drawing from socio-technical systems and sociomateriality (Leonardi, 2013), structuration theory (Orlikowski \& Robey, 1991), and complexity theory (Braa, Hanseth, Heywood, Mohammed, \& Shaw, 2007) all engage with social systems. Indeed, systems thinking is deeply imbedded in IS design and methodology, which in turn shapes the way we conceive of organizations. We might argue, therefore, that many of the key insights from general systems thinking have become 
part of the IS lexicon. While the links back to GST as a source for these ideas may be neglected, IS remains enriched due to its adoption and absorption of many of the tenets that Demetis and Lee offer....In summary, GST did not simply fall out of favor out of mindless neglect. Systems science is already deeply imbued in IS thinking and research.

If indeed systems science is "deeply imbued" in IS thinking and research then it is so deeply imbued as to be unrecognizable and undetectable. One would be at pains to reconstruct any set of requirements for systems theorizing from existing IS research. The point that we are making is not for systems theorizing to remain, if it is present at all, “deeply imbued” and perceived as having “crept into" IS research, but instead for systems theorizing to be conducted explicitly. This establishes the need to openly and ardently discuss the requirements for systems-theoretical research within IS and we would agree with Robey and Mikhaeil on the need to explore the reciprocal requirements that IS artifacts would impose on systems science (p.129).

In a manner similar to the above, Mingers notes that "the current paper attempts this task for systems theory," namely, the task of asking what implications does the approach of systems theory have for crafting theory, "but is too narrow and rather old-fashioned for it to successfully do justice to such a rich and vibrant field.” (p. 67) But from the perspective of information systems, has the field of systems theory indeed been rich and vibrant?

As already noted, there has existed no overall body of literature indicating a general acceptance and broad application of systems theory in the information systems field. Apart from the few individual exceptions noted, the term "systems" in information systems has been an empty honorific, where the phrase "information systems" is largely interchangeable with "information technology" or even just "the computer."

\section{The supposed overall neglect of systems science}

Another important reflection is given by Robey and Mikhaeil in their claim of "overall neglect of systems science.” While this might be taken as a parenthetical remark, we elect to address it in order to emphasize that systems science has reinvigorated other disciplines and showcase its potential toward that end. A recent example is systems biology that builds (in part) on early systemic principles (Ashby, 1958; Wiener, 1948; Wiener \& Schadé, 1965); this 
has led top academic institutions to embrace such programmes. Harvard Medical School for instance has a Department of Systems Biology with courses where dynamical systems theory is used as a tool to understand molecular and cellular biology. Oxford and Cambridge Universities (and many more), have similar programmes. Systems biology is defined as "the study of biological systems whose behaviour cannot be reduced to the linear sum of their parts’ functions” (Nature, 2017), an idea dismissed by Mingers as a "well-worn catch phrase” (more on that in section 5). Thus, to say that systems theory has been subject to overall neglect is not accurate. It is the field of IS that has neglected systems science.

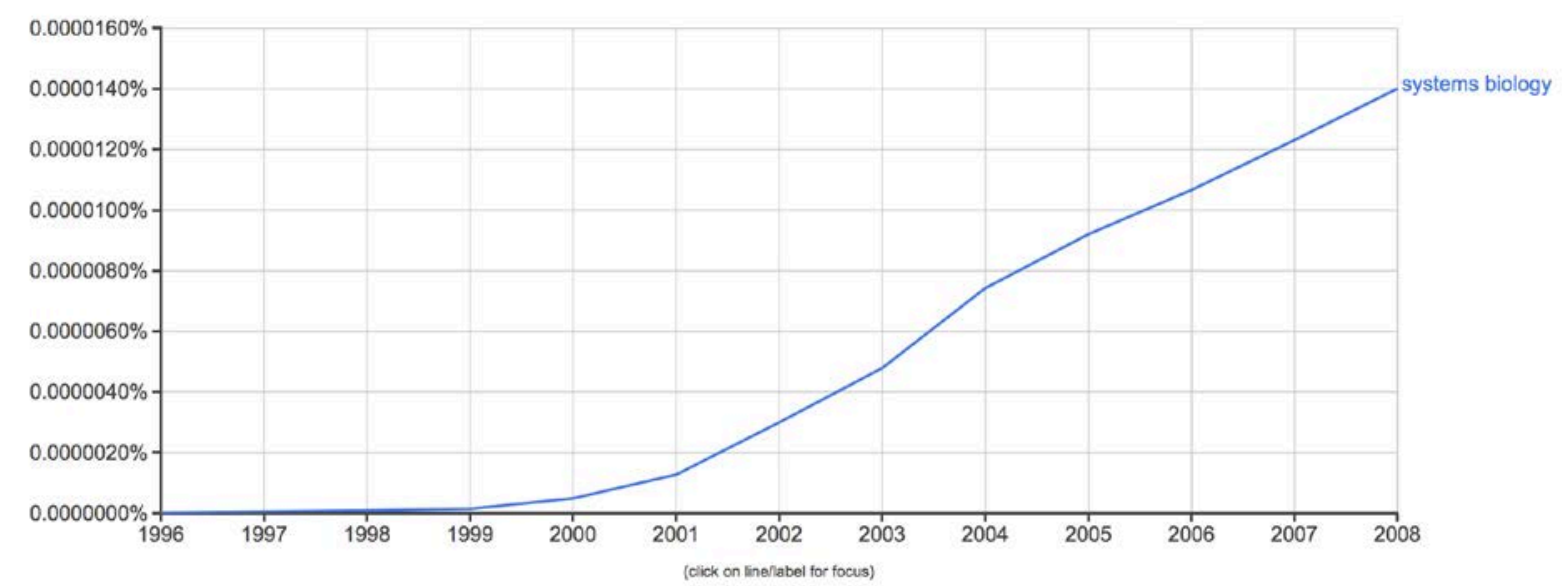

Figure 1: Google Analytics on Google scanned books corpus The emergence of systems biology

While a detailed bibliometric analysis would be warranted in order to support the statements about systems theory and information systems in full, we ran a query based on the Scopus database by keyword only ("systems theory" or "systems thinking”). Then, we filtered the results for journal articles that would belong to any of the journals of information management as these are listed in the latest Association of Business Schools (ABS) list. This includes the 72 journals on the ABS list (including the AIS senior scholars basket of eight). 


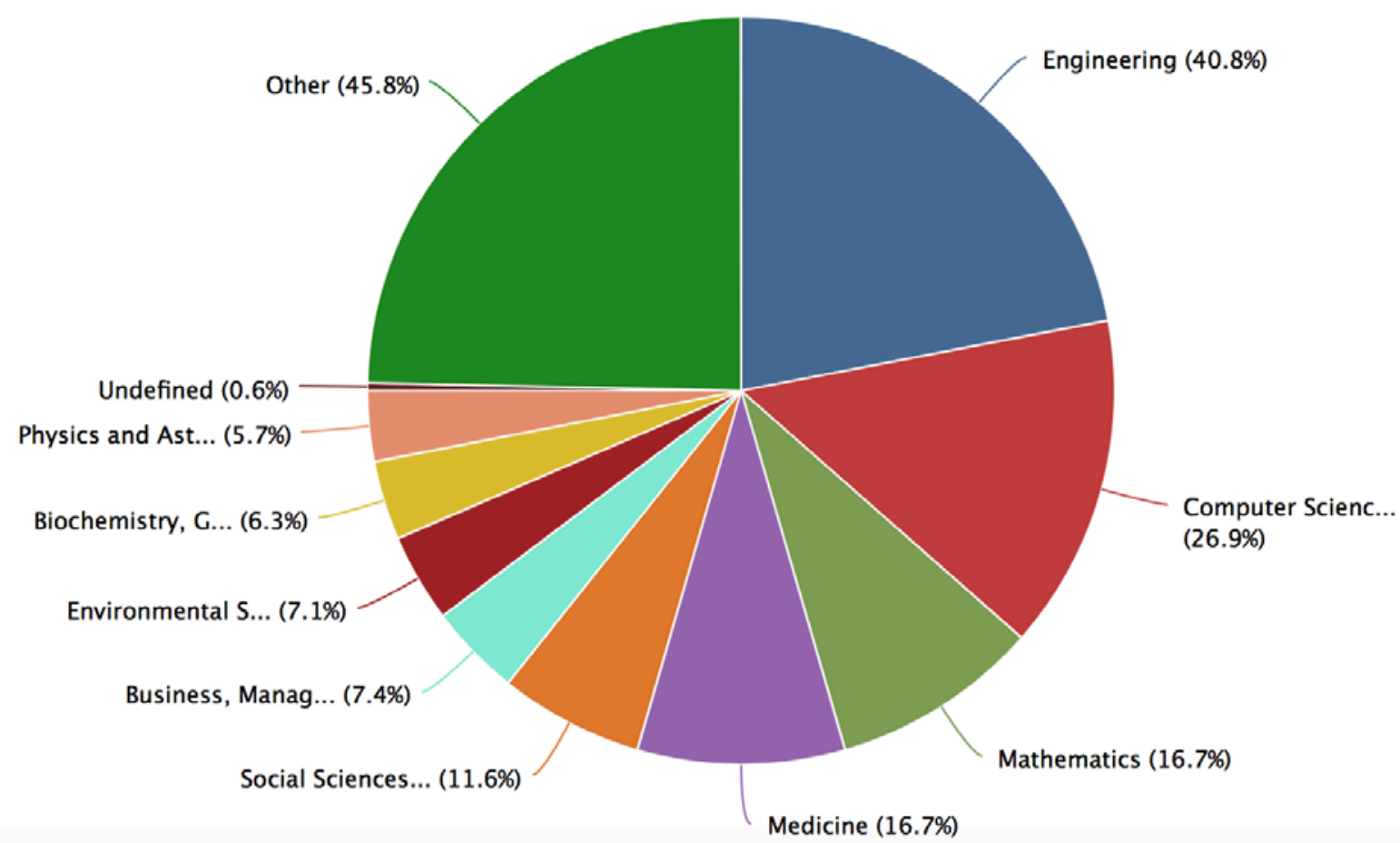

Figure 2: "systems theory" or "systems thinking” journal article distribution based on subject area ( $n=21335$ documents) - 35 years span (percentages add up to more than $100 \%$ as some articles are tagged in multiple subject areas)

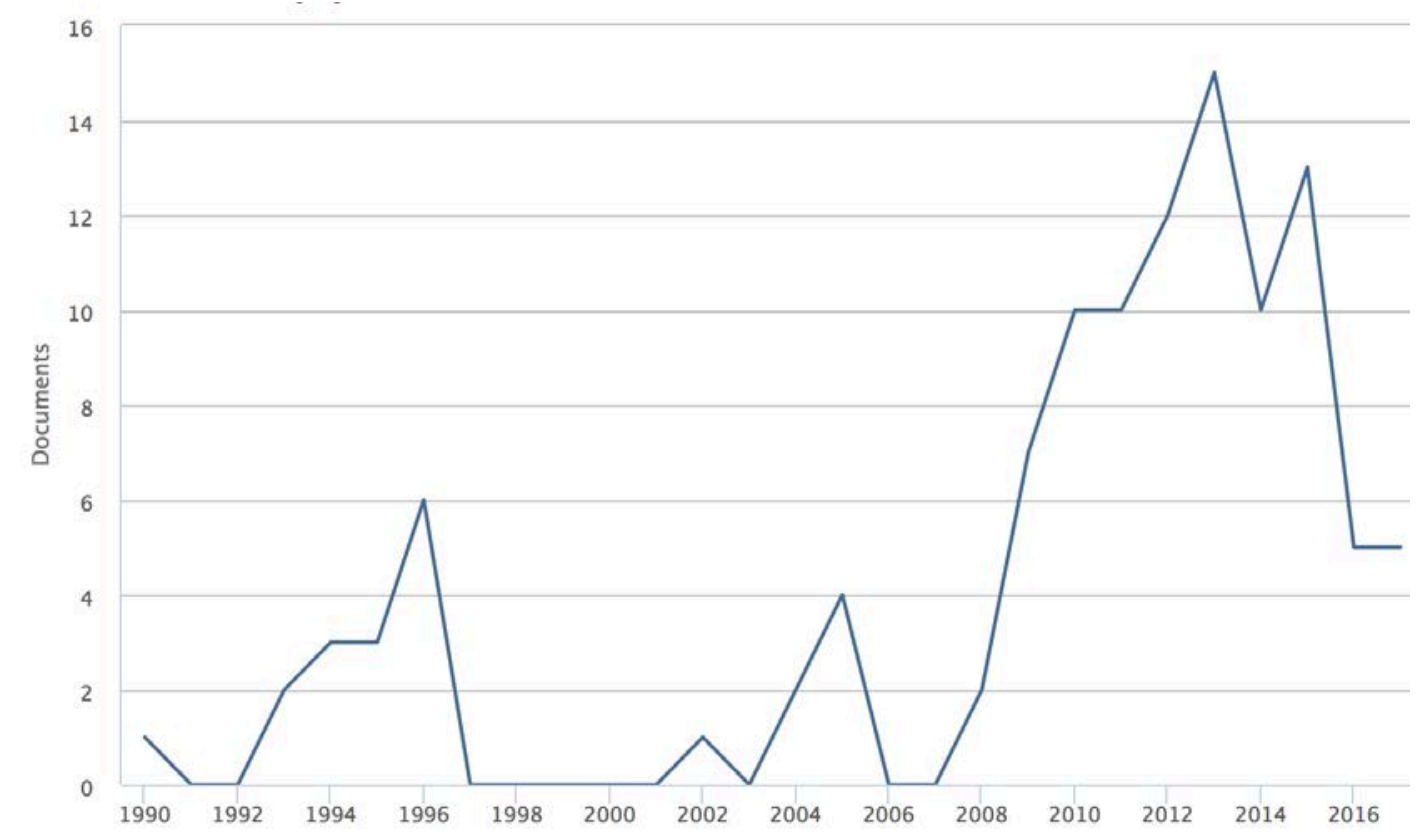

Figure 3: IS-based journal articles on systems theory/systems thinking ( $\mathrm{n}=111$ documents) over a 25 year period - ABS list of journals

Once again, we emphasize that due to multiple filters applied and several variations in

bibliometric database structures, the above diagrams are only indicative; but in both 
scenarios, we find that these indications to alert us to a simultaneous uptake of systems theory across disciplines but a lack of uptake in information systems.

\section{The communicability of systems theory and the path of grand theories}

Another interesting aspect that Robey and Mikhaeil reflect on is depicted in the following quotation (p. 128):

... we find Demetis and Lee's claim that systems science could facilitate communication between academia and industry to be puzzling. Given the abstractness and complicatedness of both GST and Luhmann, they would seem to exist alongside of Giddens' structuration theory (Giddens, 1984) as examples of arcane academic language rather than appealing alternatives, as Demetis and Lee suggest. Checkland, 2000, acknowledged by Demetis and Lee as an exemplary application of systems science, succeeds more as a methodology for analyzing socio-technical systems and less as a theory upon which research can be based. We have no argument with the value of Checkland's work and its impact on practice, but it would seem unfair to claim that Demetis and Lee's GST and LST principles, which lack lay terminology, would be easily understood by IS practitioners.

On the issue of communication between academia and industry and the role of systems theory therein, we offer some additional thoughts in order to explain our assertion.

Systems theory does not reside alongside Giddens' structuration theory as suggested, either in complexity or in the degree of abstraction. The very fact that systems theoretical concepts/constructs have actually transcended law, sociology, economics, engineering, physics, biology, chemistry, mathematics, etc., demonstrates the existence of a crossdisciplinary language that can be adopted from one domain to another. If in turn we consider IS professionals, then - assuming these are people with university degrees - they would have studied in one of the many fields that has found some degree of semantic interoperability with systems theory. This has a complementary dimension: the set of systems requirements that we put forward have closer semantic correspondence to the issues that IS practitioners face (than structuration theory for instance). Systems concepts can be better understood by IS professionals as these concepts are native to the multidisciplinary pool of background disciplines that the IS professionals have studied. For example, when someone develops his/her background in computer science, or biology, or physics, or industrial engineering or anything else, they develop their thinking based on principles, structures, phenomena that they are taught. Whether they learn about a client-server architecture, or how a human cell uses its membrane to control the movement of substances in and out of the cell, or earth and 
its moon, or indeed, a company and its business context, they can relate to what they could loosely identify as a system (e.g. a server, a single cell, earth, a company) and its environment (e.g. clients, other cells/structures in the human body, the moon, the business context).

More critically, the systems-theoretical ideas that transcend different disciplines are the product of cross-discipline syntheses that have occurred over decades in the hope of delivering abstract/generalizable constructs and developing overarching systemic principles. We admit that there are some more difficult concepts within systems theory (like autopoiesis and self-reference), but we would be glad to pit the basic concepts of systems theory (like the difference between a system and its environment, boundary, and feedback) against the mental gymnastics of structuration. Also, we must not forget that while structuration has been developed by a sociologist, for sociology, and adopted by IS, the corpus of systems theoretical ideas (with its different branches) has been created in a bottom-to-top approach by a variety of disciplines. This is a radically different trajectory from other theories (like structuration) that have not been "designed" to accommodate cross-disciplinary communication; in that context, since the IS field attracts scholars from different backgrounds, we find the correspondence between IS and systems theory to be particularly attractive. Of course, it is up to IS researchers to explore how they can use our concepts (and those of others) to develop, as a second step, more detailed applicable/customisable methodologies at a similar level with Checkland's. These would enable a closer coupling between academia and industry. We contend that the same does not and cannot apply to theories like structuration - exactly because their degree of abstraction cannot facilitate such communication.

We would agree with Robey and Mikhaeil that "Organization studies and IS have generally eschewed grand theory in favour of mid-range or grounded theorizing" as these are "deemed more practical and manageable” (Robey \& Mikhaeil, 2016, p.128), but one may readily argue against a continuation of this approach. The inexorable trend towards mid-range theorizing for having manageable domain-specific descriptions has created a massive theoretical complexity which has in fact become unmanageable. It has created an asymmetry that becomes counter-productive. A good example is the technology acceptance model (TAM) for which Hovorka and Larsen (2017, p.5710) “estimate that thousands of extension papers have been published, most of which do not build upon or cite each other. This means that while the core concepts remain the same, each paper will add other constructs, and these constructs do 
not retain a consistent set of names”; these TAM-extensions (estimated at approximately 5,000 claimed “original contributions”) create a considerable demand toward theory integration as Hovorka and Larsen remind us. We would add that systems theory has already been through the process of construct-integration at a cross-disciplinary level; thus, despite some variations, there is consistency amongst its fundamental theoretical constructs. These have been developed in order to transcend fields and can therefore be reapplied to them, including in IS; furthermore, they can function as a theoretical vehicle for the reduction of such mid-range complexity, if adopted.

\section{On emergence, the observer, and other considerations}

One of the most critical concepts that are elevated within systems theory is the concept of emergence. In brief, the concept of emergence goes against reductionism and describes how new qualitative phenomena spring from the interconnection of different elements; such (emergent) phenomena cannot be attributed to their constituent parts. This is the spirit of the "whole being greater than the sum of its parts." Mingers says that "Most of these concepts are discussed by Demetis and Lee (2016) except, interestingly, emergence” (p.68); however, we noted that "What we casually call an 'information system' is therefore, in this light, an emergent phenomenon.” Interestingly, our essay offered the preceding statement to cap off a discussion of "the whole is greater than the sum of its parts," which is paradoxically written off by Mingers as a well-worn catch phrase. This is exactly why we did not offer this phrase in isolation. We noted: "Worth emphasizing are systems science’s three interrelated features that 'the whole is more than the sum of the parts,' 'the parts are dynamically interrelated or interdependent,' and 'holistic properties not possible to detect by analysis should be possible to define in the system.' " In other words, the very idea that the "whole is greater than the sum of its parts” is the epitome of emergence. It is an expression that signifies a qualitative shift from the micro-level to the macro-level. It is also a recognition of something that cannot be attributed to the individual parts that interconnect and can be recognised to define a system as a whole (by an observer).

A more elaborate point on the relationship between systems/environments is offered by Robey and Mikhaeil who discuss the following (p. 129): 
While both GST and LST clearly delineate systems from their environments, and focus on the relationship between open systems and their environments, they hold fast to a traditional view of organizations (systems) that can be challenged. With the advent of technical platforms that transcend organizations, that belong to no one in particular, and are created and used by a diffuse set of actors, thinking about IS and organizations needs to be revised. GST poses that systems at all levels have the same characteristics (a multilevel theory) (Staw, Sandelands, \& Dutton, 1981), and it reinforces the idea that each level is distinct and self-contained. Neither GST nor Luhmann focus on relationships across levels (cross-level theory) (Rousseau, 1985). Winter et al. (2014) give us a new option by challenging the container view of organizations and offering an unbounded view of IS and its capacity to redefine what organizations are.

While Luhmann's impact on organization studies has been the subject of substantial discussion (Seidl \& Becker, 2006, 2009), the distinct nature of systems, including any feature of self-containment, is not fixed but observer-relative. Nothing precludes the possibility of defining a system that includes multiple cross-level subsystems. We would agree with Robey and Mikhaeil that the advent of technical platforms transcends organizations but emphasize that Luhmann discusses that operative closure is coupled with the idea that systems remain informationally open. This is connected to a number of other concepts including interconnectedness but this is also based on systemic decomposition. For example, while the traditional view of systemic deconstruction perceives systems as a collection of sub-systems and sub-subsystems ad infinitum, Luhmann distinguishes between that view (we could call that the "classic" view of systems differentiation) and a view that perceives systems as a connection of elements and relations between these elements. The latter is a lot closer to a "networked" perspective and leads to the concept of system complexity. This opens the door for perceiving technology as a conduit of relationships "across levels" and in fact explores technology as a system in its own right (what Robey and Mikhaeil suggest as differentiated as a "technical system"). In another paper we have authored (Demetis \& Lee, 2017), we lay part of these foundations by exploring the role-reversal between human agency and technology within the society/technology coupling; we argue that humans can now be considered as agents of a system of technology, moving the theoretical discussion closer to treating technology as a system.

But there is another important consideration based on the distinction between system/environment. As Luhmann notes, "By defining a system, a conceptual boundary is unavoidably set; for without the boundary, the system would have been impossible to start with. Boundaries then cannot be conceived without something beyond and thus their very 
existence presupposes the reality of a beyond and the possibility of transcendence” (Luhmann, 1995, p.43). So while the definition of a system "isolates" elements (based on an observer-relative perspective), it does not do the same for relations. Put differently, the boundary has the double function of both separating and connecting system/environment.

\section{Systems theory from the perspective of sociomateriality}

The reaction by Schultze (2017), rooted in sociomateriality, takes a different trajectory and provides a lengthy and substantive commentary that dives deep into the relationship between reality and theory. While the focus of Schultze's commentary is built upon a relational ontology and differs in that it reflects on deeper assumptions about the relationship between reality and theory, there are a few aspects that Schultze emphasizes which we would like to address. In this context, we would like to offer some general comments that we feel are important specifically in the context of our essay and more generally in relation to what we had set out to do in the first place.

Based on our reading, the main concerns of Schultze are succinctly summarised in the following quotation (Schultze, 2017, p.64):

the reality that systems science seems to produce emerged as one dominated by static entities that are brought into orderly vertical (i.e. hierarchical decomposition) and horizontal (i.e. input-output) relationships with one another. Even though system science stresses interdependence and abstractions of complex wholes, these relationships are layered on top of the independent, static and agential components that make up a system.

First, we would like to address the issue of independent components that make up a system, though this is to some degree related to the assertion that we posit static components. We would argue that the emphasis on interdependence is not just overlaid on top of independent components. Interconnections are weaved into the basic structure of the latest developments in systems theory. As Bechmann and Stehr (2002, p.70) remind us: "Luhmann proceeds from a system concept shaped in a strictly relational manner [emphasis added]. His notion relies on the idea of a constitutive boundary that permits the distinction between inside and outside. 
Each operation of a system (in the case of social systems: each communication) (re)produces this boundary by embedding itself in a network of further operations, in which it at the same time gains its own unity/identity.” This concept of re-production, an essential basis for autopoietic, self-referential systems, portrays systems as dynamic entities that re-produce themselves in a dynamic manner through the network of complex interrelationships that bind them together.

While for analytical purposes we may choose one configuration of elements/relations over another (e.g. in our Anti-Money Laundering case), these essentially represent the choice of an observer and prompt both second order observations and re-observations from other perspectives. The primacy of the observer as a distinction-creating entity must not be forgotten in this context as "whenever an observer observes, he creates a contingent distinction between what is observed and what is by necessity left unobserved. The complexity of the real world that is observed rests upon this stratum of such contingent distinctions” (Angell \& Demetis, 2010, p.174).

A good example of this is given by Luhmann in his book The Reality of the Mass Media which reminds us that any distinction can be subjected to different deconstructions by different observers (Luhmann, 2000). For example, the distinction between true/false has a different use-value when it is examined, used and interpreted from the perspective of the system of science than what it has when viewed from the system of theology or the system of law. This implies that the use-value of any distinction that is to be deconstructed is contingent upon the observers that attempt this act of deconstruction. This not only grants primacy to the role of the observer within LST but also implies that distinctions are contingent on the observing system that identifies them. This then opens the door for observers of observers (second order observers). An example related to Anti-Money Laundering can help us illustrate this further. For instance, terrorist organisations are part of the AML compliance regime as terrorists are dependent on both legal and illegal money in order to fund their terrorist operations. But different institutions (e.g. banks, political organisations, NGOs) approach the monitoring of terrorist financing differently. In this case, we could say that the distinction between terrorists/non-terrorists is a single distinction that can have multiple observers. This is a difference that can be subjected to a further difference however - the French term différance is reserved for this condition (Luhmann borrows this term from Jacques Derrida). This implies that the meaning captured in the unity of the distinction between terrorists/non-terrorists can be deferred not only to first order observers (e.g. the banks, political organisations, NGOs) but also to second order observers. It is only by 
observing the observation of first order observers (i.e. conducting a second order observation) that we can deconstruct the observations of the first order observers.

Of course, second order observers "construct" distinctions too: they observe with cognitive and other biases that colour the deconstruction of first order observers. But second order observers serve a unique function (and role) in delineating the conditions and the differences that the exact same distinction (i.e. terrorists/non-terrorists) may be approached by the first order observers. They point to the contingency that first order observers observe/designate/identify a “different object.” As Luhmann mentions, “the illusion to be deconstructed is the assumption that all these systems designate the same object when they use a distinction” (Luhmann, 2002). In fact, the stereotypicality of any such distinction (e.g. terrorist/non-terrorist) makes it difficult to recognise the different layers of observercontingent differences that are at play. In a sense, it is no surprise that Luhmann chose mass media as a fruitful application domain to highlight how first order observers are bombarded with stereotypical distinctions and how second order observing could unpick the different contingencies assumed and subsumed in the portrayal of such distinctions. Put differently, it is only when one introduces a second order observer that a multiplicity of first order observers can come into focus (e.g. and ultimately the distinctions that they use to observe an object). Deconstructing any problem domain then becomes an exercise in second-order observing. This pits relationality in systems theory against a grid of observing systems that can be re-observed. A good reading that highlights some of these aspects is the book chapter, “Deconstruction as Second-Order Observing” (Luhmann, 2002, pp.94-112).

We would supplement this with Gregersen's quotation (in a theological research context where systems theory has also been applied) that: "this turn from a substantialist ontology toward a relational ontology marks a paradigm shift in systems theory as well as in theology” (Gregersen, 1998). Thus, when Schultze states that “a relational ontology regards reality in 'dynamic, continuous and processual terms' rather than in substantialist (or essentialist) ones (Emirbayer, 1997)," we too would argue for the former (the relational) but note that systems theory's explicit observer-relative emphasis, coupled with its stream of second order observation, makes a lucid rendition of relationality: one built upon the distinctions and differences of different observers. 
Overall, the conclusions that Schultze draws can be described as overgeneralizing from the one case we offered as merely being illustrative. Might there be other cases which formulate systems theory in ways compatible with sociomateriality? This is an open question. Schultze notes, "In summary, the world that systems science seems to be producing is one of things whose identities and boundaries are quite stable.” (p.63). As analysed above, one could readily offer a different formulation of systems theory, including Luhmannian systems theory, of things whose identities and boundaries are not quite stable. Again, the main point is to consider the formulation of systems theory in the Demetis and Lee essay as but a single case that should not be overgeneralized as offering universal criteria for what constitutes systems science.

On another important matter, Schultze makes the point, "a key consequence of this perspective is that we can shape reality through the theories and methods we adopt,” and raises the question, “What kind of reality does systems science produce?” (p.60) We recognize this as an empirical question. Schultze dwells on some of the details from the Drosia bank case, but there are in fact numerous other examples of reality produced by systems science. For this, we can turn to the many examples available from the field work of Checkland's soft systems methodology or SSM (for an introduction to examples of SSM field work, see (Checkland \& Poulter, 2006)), which itself is a form of action research. If we were to ask: "Has SSM been applied to shape realities in ways that can be considered beneficial?”, certainly proponents of SSM would answer yes. This should alleviate concerns that Schultze has about the high stakes of advocating and adopting the lens of systems theorizing. Of course, the kind or kinds of reality produced by SSM might or might not conform to the kind of reality approved by proponents of sociomateriality, but then, neither SSM in particular nor systems science in general has purported to be consistent with the principles of sociomateriality. In fact, as an intellectual exercise, one might even turn the tables: to what extent may we judge sociomateriality as living up to the principles of systems science? Perhaps the lesson is that neither should be privileged over the other.

Finally, we must draw attention to Schultze’s misunderstanding that, in our essay, “six requirements that need to be satisfied for an IS study to qualify as systems science, are developed and empirically demonstrated." As mentioned previously, we emphasized in different parts of our essay that our set of requirements is not a "universal set of systems criteria but just one possible set out of many" (p.126) and that "the purpose is not to present 
all features of systems science” (p.116). We caution that our call for greater systems theorizing, which we merely illustrate with principles from GST and LST, should not be reified into a recipe.

The commentaries of Robey and Mikhaeil, of Mingers, and of Schultze are all useful for indicating the range of reactions to the systems theorizing we advocate for IS research. Where the reaction is that it crept into IS research where it remains deeply imbued, we prescribe that it move into a role where it is conducted explicitly. Where the reaction is that it is old fashioned, we recommend patience so that it may advance one step at a time. Where the reaction is that it does not necessarily help to make a kind of world that is desirable, we emphasize that there are many forms of systems theorizing, and the kinds of worlds that they make are likely to span a wide range.

\section{References}

Alter, S. (2001). Are the fundamental concepts of information systems mostly about work systems? . Communication of AIS, 5, 1-67.

Angell, I., \& Demetis, D. (2010). Science's First Mistake: Delusions in pursuit of theory. London, New York, : Bloomsbury.

Ashby, W. R. (1958). An introduction to cybernetics. London: Chapman and Hall.

Bechmann, G., \& Stehr, N. (2002). The legacy of Niklas Luhmann. Society, January/February

Braa, J., Hanseth, O., Heywood, A., Mohammed, W., \& Shaw, V. (2007). Developing health information systems in developing countries: The flexible standards strategy. MIS Quarterly, 31, 381-402.

Checkland, P. (2000). Soft Systems Methodology: A Thirty Year Retrospective. . Systems Research and Behavioral Science, 17, 11-58.

Checkland, P., \& Poulter, J. (2006). Learning for Action: John Wiley \& Sons.

Demetis, D., \& Lee, A. (2016). Crafting theory to satisfy the requirements of systems science. Information and Organization, 26, 116-126.

Demetis, D., \& Lee, A. (2017). When humans using the IT artifact becomes IT using the human artifact. In 50th Hawaii International Conference on System Sciences Hawaii, United States: HICSS.

Emirbayer, M. (1997). Manifesto for a Relational Sociology. American Journal of Sociology, 103, 281-317.

Giddens, A. (1984). The constitution of society : outline of the theory of structuration. Polity press, Cambridge, 174-175,. 
Gregersen, N. H. (1998). The idea of creationa and the theory of autopoietic processes. Zygon, 33, 333-367.

Hovorka, D., \& Larsen, K. (2017). Modes of Theory Integration. In 50th Hawaii International Conference on System Sciences (pp. 5709-5716). Hawaii.

King, M., \& Thornhill, C. (2003). 'Will the real Niklas Luhmann stand up, please'. A reply to John Mingers. The Sociological Review, 51, 276-285.

Leonardi, P. M., 23, 59-76. (2013). Theoretical foundations for the study of sociomateriality. Information and Organization, 23, 59-76.

Luhmann, N. (1995). Social systems. Stanford, Calif: Stanford University Press.

Luhmann, N. (2000). The Reality of the Mass Media. Cambridge: Polity Press.

Luhmann, N. (2002). Deconstruction as Second-Order Observing. In Theories of Distinction: Redescribing the descriptions of modernity (pp. 94-112): Stanford University Press.

Mingers, J. (2017). Back to the future: A critique of Demetis Lee's "Crafting theory to satisfy the requirements of systems science". Information and Organization, 27, 67-71.

Nature. (2017). Systems biology. In.

Orlikowski, W., \& Robey, D. (1991). Information technology and the structuring of organizations. Information Systems Research, 2, 143-169.

Robey, D., \& Mikhaeil, C. A. (2016). Déjà Vu or Art Nouveau? A comment on Demetis and Lee's "Crafting theory to satisfy the requirements of systems science". Information and Organization, 26, 127-130.

Rousseau, D. M. (1985). Issues of level in organizational research: Multi-level and cross-level perspectives. Research in Organizational Behavior, 7, 1-37.

Schultze, U. (2017). What kind of world do we want to help make with our theories? Information \& Organization, 27, 60-66.

Seidl, D., \& Becker, K. H. (2006). Organizations as Distinction Generating and Processing Systems: Niklas Luhmann's Contribution to Organization Studies. Organization, 13, 935.

Seidl, D., \& Becker, K. H. (2009). Introduction: Niklas Luhmann and Organization Studies. In Niklas Luhmann and Organization Studies (pp. 8-20): Copenhagen Business School Press.

Staw, B. M., Sandelands, L. E., \& Dutton, J. E. (1981). Threat rigidity effects in organizational behavior: A multilevel analysis. Administrative Science Quarterly, 26, 501-524.

Wiener, N. (1948). Cybernetics. New York,: J. Wiley.

Wiener, N., \& Schadé, J. P. (1965). Cybernetics of the nervous system. Amsterdam, New York,: Elsevier Pub. C.

Winter, S., Berente, N., Howison, J., \& Butler, B. (2014). Beyond the organizational 'container': Conceptualizing 21st century sociotechnical work. Information and Organization, 24, 250-269. 